\title{
COMMENT
}

\section{Female-biased sex ratios in marine pelagic copepods: Comment on Gusmão et al. (2013)}

\author{
A. G. Hirst ${ }^{1, *}$, D. Bonnet ${ }^{2}$, D. V. P. Conway ${ }^{3}$, T. Kiørboe ${ }^{4}$ \\ ${ }^{1}$ School of Biological and Chemical Sciences, Queen Mary University of London, London E1 4NS, UK \\ ${ }^{2}$ Laboratoire ECOSYM, UMR5119, Université Montpellier 2, CC093, Place Eugène Bataillon, 34095 Montpellier Cedex 05, France \\ ${ }^{3}$ Marine Biological Association of the United Kingdom, Plymouth, Devon PL1 2PB, UK \\ ${ }^{4}$ National Institute for Aquatic Resources, Oceanography Section, Technical University of Denmark, 2920 Charlottenlund, \\ Denmark
}

\begin{abstract}
Gusmão et al. (2013; Mar Ecol Prog Ser 482:279-298) review causes of sex ratio skew in pelagic copepods and in doing so repeatedly dispute the paper of Hirst et al. (2010) 'Does predation control adult sex ratios and longevities in marine pelagic copepods?' Here we respond to some important errors in their citation of our paper and briefly highlight where future work is needed in order to attribute the causes of strong sex ratio skew seen in some copepod families.
\end{abstract}

KEY WORDS: Predation · Physiological longevity · Sex ratio skew

\section{Correct citation}

In establishing their objective, to test whether adult sex ratio skew in pelagic copepods is the result of predation, Gusmão et al. (2013, p. 280) quote Hirst et al. (2010) as: 'adult sex ratio skew in pelagic copepods is primarily due to differential mortality of the sexes [greater predation on males] in the adult stage and not juveniles'. However, their bracketed addition substantively changes the meaning of our text. By removing their insertion, the original meaning is re-instated: adult sex ratio skew is largely due to adult mortality - not simply from predation, but physiological mortality as well. The sentence is there to clarify when, on average, sex ratios become skewed; we identify that skewed sex ratios commonly arise in the adult stage, but not before. Such identification is an important step in determining the causes of the skew. In Hirst et al. (2010), we quantify both physiological and predation mortality in adults (see e.g. Figs. 4 to 9 and
Eqn. 4a,b in Hirst et al. 2010) and emphasise the importance that physiological longevity (longevity in the absence of predation mortality) has in controlling sex ratio. The specific nature of our findings is clear from our conclusions (Hirst et al. 2010, p. 2203): 'The indirect approach we have adopted here suggests that sex skew arises predominantly in adults, that predation on the adults is a major contributor to field mortality, and that predation mortality is found to generate much of the sex ratio skew in Pseudocalanus and Oithona.' Predation is important to adult mortality, both in females and in males; predation being important does not infer a bias towards one sex or the other. Further, only in 2 genera, Pseudocalanus and Oithona, do we find that predation mortality is the dominant cause of the sex skew (Hirst et al. 2010). Gusmão et al. (2013) incorrectly state that our paper concludes that predation is the main factor controlling adult copepod sex ratios, whereas our conclusions are much more specific than this representation. 


\section{Skewed sex ratios}

Testing whether predation causes female-biased sex skew in the field is best answered by examining those species in which such sex ratios are consistently and strongly skewed towards females, and ideally where adults show marked differences in their reproductive behaviour (this is the basis of the hypothesis of predator-determined sex ratio skew presented in Kiørboe 2006). In arriving at the title 'No evidence of predation causing female-biased sex ratios in marine pelagic copepods', Gusmão et al. (2013) draw much data from copepod families in which, on average, there are no strong consistent sex ratio biases, including the families Acartidae, Temoridae, Centropagidae and Oncaeidae (see Fig. 7 in Hirst et al. 2010). Species from these families dominate Gusmão et al.'s (2013) Table 3 for example, in which sexual biases in predator selection are tested, and such species are used throughout the paper. In order to test whether predators remove more males than females, new studies which combine field and experimental approaches are needed, and these are best focussed on the heavily female-biased families.

\section{Study of predation effects}

In Hirst et al. (2010) we considered the degree to which predators cause sex skew in adult copepods as

Editorial responsibility: Christine Paetzold, Oldendorf/Luhe, Germany an open-ended, elusive question. Gusmão et al.'s (2013) title contradicts the results from our quantitative approach for 2 genera, and some of the predator preference data that they themselves reference (namely Ohman 1986, Saito \& Kiørboe 2001). Sex ratios and the attribution of skew have historically been understudied, especially given their importance to the population dynamics of marine pelagic copepods (Hirst \& Kiørboe 2002, Kiørboe 2006); it is premature to exclude predation as a driver of skewed sex ratios in marine copepods.

\section{LITERATURE CITED}

Gusmão LFM, McKinnon AD, Richardson AJ (2013) No evidence of predation causing female-biased sex ratios in marine pelagic copepods. Mar Ecol Prog Ser 482: 279-298

> Hirst AG, Kiørboe T (2002) Mortality of marine planktonic copepods: global rates and patterns. Mar Ecol Prog Ser 230:195-209

> Hirst AG, Bonnet D, Conway DVP, Kiørboe T (2010) Does predation control adult sex ratios and longevities in marine pelagic copepods? Limnol Oceanogr 55:2193-2206

- Kiørboe $\mathrm{T}$ (2006) Sex, sex-ratios, and the dynamics of pelagic copepod populations. Oecologia 148:40-50

> Ohman MD (1986) Predator-limited population growth of the copepod Pseudocalanus sp. J Plankton Res 8:673-713

> Saito H, Kiørboe T (2001) Feeding rates in the chaetognath Sagitta elegans: effects of prey size, prey swimming behaviour and small-scale turbulence. J Plankton Res 23: 1385-1398

Submitted: May 23, 2013; Accepted: August 19, 2013

Proofs received from author(s): August 21, 2013 